\title{
Effect of exercise on bone in poorly controlled type 1 diabetes mediated by the ActRIIB/Smad signaling pathway
}

\author{
JIN YANG ${ }^{1,2}$, LIJUN SUN $^{3}$, XIUSHAN FAN ${ }^{3}$, BO YIN ${ }^{3}$, YITING KANG $^{3}$, LIANG TANG $^{3}$ and SHUCHENG AN ${ }^{2}$ \\ ${ }^{1}$ Department of Physical Education, Xi'an University of Posts and Telecommunications, Xi'an, Shaanxi 710121; ${ }^{2}$ College of \\ Life Sciences, Shaanxi Normal University, Xi'an, Shaanxi 710062; ${ }^{3}$ Institute of Sports Biology, \\ Shaanxi Normal University, Xi'an, Shaanxi 710119, P.R. China
}

Received September 13, 2017; Accepted August 1, 2018

DOI: $10.3892 /$ etm.2018.6601

\begin{abstract}
Myostatin (MSTN) is not only a key negative regulator of skeletal muscle secretion, however is also an endocrine factor that is transmitted to bone. To investigate the effect and possible mechanism of weight-bearing treadmill running on bone with poorly controlled Type 1 diabetes, rats were randomly divided into three groups: Normal control (NC), diabetic mellitus (DM) and diabetic exercise training groups (DM-WTR). The DM-WTR rats were trained with weight-bearing running. The results demonstrated that the levels of serum insulin, body weight, bone mass, muscle mass, grip strength, and serum calcium in the DM-WTR rats were significantly increased, whereas the levels of blood glucose, alkaline phosphatase, and tartrate-resistant acid phosphatase were markedly reduced in the DM-WTR rats compared with the DM rats. Weight-bearing running inhibited streptozocin (STZ)-induced MSTN mRNA and protein expression in the diabetic rats. The mRNA and protein expression levels of activin type IIB receptor and mothers against decapentaplegic homolog 2/3 and its phosphorylation in femur DM-WTR rats were reduced compared with DM rats. In addition, weight-bearing running enhanced the STZ-induced Wnt and $\beta$-catenin expression levels and reduced the STZ-induced glycogen synthase kinase (GSK)-3 $\beta$ expression in diabetic rats' femora. In conclusion, the results suggested that weight-bearing running could partially ameliorate STZ-induced femur atrophy via MSTN downregulation, and this may be associated with the inactivation of Activin A Receptor Type $2 \mathrm{~B} / \mathrm{Smad} 2 / 3$ signaling
\end{abstract}

Correspondence to: Professor Liang Tang, Institute of Sports Biology, Shaanxi Normal University, 620 West Chang'an Avenue, Chang'an, Xi'an, Shaanxi 710119, P.R. China

E-mail: 1762684034@qq.com

Professor Shucheng An, College of Life Sciences, Shaanxi Normal University, 620 West Chang'an Avenue, Chang'an, Xi'an, Shaanxi 710062, P.R. China

E-mail: shuchengan@snnu.edu.cn

Key words: weight-bearing treadmill running, bone, myostatin, STZ-induced diabetes pathways and the activation of the Wnt/GSK $3 \beta / \beta$-catenin signaling pathway. Further studies are needed to verify these conclusions.

\section{Introduction}

The pathogenesis of Type 1 diabetes mellitus (T1DM) is mainly due to the lack of insulin production secreted by the pancreas $(1,2)$. Bone metabolism disorder is one of the complications of T1DM, and it leads to a change of microstructure $(3,4)$, a reduction of bone mass, and an increase in the probability of fracture (5), finally resulting in metabolic bone diseases (6).

As early as 1927, Morrison stated that participants who had metabolic syndrome as children were about 13 times more likely to have cardiovascular disease and 6.5 times more likely to have type 2 diabetes than the participants who did not have metabolic syndrome as children (7). There is growing evidence showing that diabetes mellitus influences skeletal metabolism. The optimal management of glycemic control reduces long-term complications (8). More and more research has determined that physical activity is associated with greater longevity and lower frequency and severity of diabetes complications in individuals with T1MD $(9,10)$; however, the mechanism is not very clear.

The Wnt/ $\beta$-catenin pathway is a bone metabolic pathway and canonical Wnt signaling relies on $\beta$-catenin activity (11). More and more studies have suggested that Wnt signaling enhances bone formation by regulating osteoblasts $(12,13)$. Activin type IIB (ActRIIB), one of the receptors of myostatin (MSTN), is expressed in osteoblasts in the tibiae of neonatal rats (14). MSTN, a member of the transforming growth factor-beta (TGF- $\beta$ ) superfamily of proteins, is a negative regulator of muscle mass (15). Furthermore, it plays a role in regulating bone mass (16). Our previous studies showed that ladder-climbing training could prevent bone loss in diet-induced obese rats by inhibiting MSTN expression (17,18); meanwhile, MSTN is not expressed and secreted in osteoblasts. Active MSTN binds to ActRIIB and could lead to the subsequent phosphorylation of Smad proteins and the initiation of gene expression, so we wondered if exercise could modulate bone metabolism in streptozocin (STZ)-induced diabetes through the inhibition of MSTN. 
In the present study, we examined the effects of weight-bearing treadmill running on bone metabolism in STZ-induced diabetes rats, and we explored the molecular mechanism of weight-bearing treadmill running and how it affects bone metabolism in diabetic rats.

\section{Materials and methods}

Animals and experimental design. Healthy male SD rats (200-220 g) were obtained from the Laboratory Animal Breeding and Research Center of Xi'an Jiaotong University (Xi'an, China), and they were housed under a controlled standard temperature $\left(22 \pm 2^{\circ} \mathrm{C}\right)$, relative humidity $(60 \pm 5 \%)$, and 12-h light/dark cycle. After 5 days of acclimation, the rats were randomly divided into the normal control group (NC, $\mathrm{n}=10$ ) and the T1D model group. Experimental T1DM was induced by a peritoneal injection of STZ $(60 \mathrm{mg} / \mathrm{kg}, 0.1 \mathrm{~mol} / \mathrm{l}$ sodium citrate buffer, $\mathrm{pH}=4.5$; Sigma-Aldrich; Merck KGaA, Darmstadt, Germany). An equal volume of buffer was injected into the control rats. Then, the blood glucose levels in vein blood samples were measured on days $1,3,7$, and 10 . The rats with blood glucose levels that were greater or equal to $16.7 \mathrm{mmol} / \mathrm{l}$ (300 mg/dl) were considered to be diabetic. Then, the diabetic rats were randomly assigned to the DM group $(n=10)$ and the DM + WTR group $(n=10$, trained with weight-bearing running, on a motor-driven treadmill at a speed of $15 \mathrm{~m} / \mathrm{min}(0$ incline) bearing $35 \%$ of their body weight mass, 5 min running and 2-min intervals between each 35-min cycles, 6 days/week for 6 weeks; Fig. 1). All of the experiments were conducted with the approval of the Ethics Committee of Shaanxi Normal University and in accordance with the Guide for the Care and Use of Laboratory Animals published by the US National Institutes of Health (NIH Publication no. 85-23, revised 1996).

Grip strength. At last week, fore-limb grip strength was measured as the maximum tensile force using a rat grip strength meter (YLS-13A; Huaibei Zhenghua Bioinstrumentation Co., Ltd., Anhui, China). Rats were tested 3 times in succession without rest and the results of the three tests were averaged for each rat.

Weight and sample preparation. After 6 weeks of treatment, the final body weight was recorded, and then the rats were killed with pentobarbital sodium at dose of $40 \mathrm{mg} / \mathrm{kg}$ wt. Blood was collected and centrifuged in order to obtain the serum fractions. Serum was stored at $-80^{\circ} \mathrm{C}$ for further analysis. After killing the animals, the femurs and quadriceps femoris were harvested and weighed, then immediately stored in liquid nitrogen and stored at $-80^{\circ} \mathrm{C}$ for RT-PCR and western blot analysis.

Biochemical analysis. Blood glucose was measured using an eBsensor Blood Glucose Monitor (Visgeneer Inc., Hsinchu, Taiwan). Serum insulin levels were measured using a commercial ELISA (EMD Millipore, Billerica, MA, USA). Serum calcium $\left(\mathrm{Ca}^{2+}\right)$, phosphorus (P), alkaline phosphatase (ALP), and tartrate-resistant acid phosphatase (TRAP) concentrations were measured by using a commercially available test kit according to the manufacturer's guidelines (Nanjing Jiancheng Bioengineering Institute, Jiangsu, China).
Reverse transcription-quantitative polymerase chain reaction (RT-qPCR). Total RNA was isolated using TRIzol reagents (Invitrogen; Thermo Fisher Scientific, Inc., Waltham, MA, USA) according to the manufacturer's instructions, and then it was reverse-transcribed using a PrimeScript ${ }^{\mathrm{TM}}$ II 1st Strand cDNA Synthesis kit (Takara Shuzo, Shiga, Japan) (19). Briefly, the RNA with $2 \mu \mathrm{g}$ was added to $12 \mu \mathrm{l}$ reaction system of reverse transcription (including $1 \mu \mathrm{l}$ oligo(dT) $)_{18}$ ) and then placed in PCR amplifier at $70^{\circ} \mathrm{C}$ for $5 \mathrm{~min}$. Then the above system was added in order $4 \mu \mathrm{l}$ 5xbuffer, $2 \mu \mathrm{l} 10 \mathrm{mM}$ dNTPs, $1 \mu \mathrm{l}$ RNA inhibitor and $1 \mu 1$ reverse transcriptase and placed in PCR amplifier at $42^{\circ} \mathrm{C}$ for $60 \mathrm{~min}$, the reaction was ended at $80^{\circ} \mathrm{C}$ for $5 \mathrm{~min}$. Gene expression was analyzed by the CFX96 Real-Time PCR Detection System (Bio-Rad Laboratories, Inc., Hercules, CA, USA). The reverse transcription products with $2.5 \mu \mathrm{l}$ was added to reaction system of PCR. And then, the products were denatured at $95^{\circ} \mathrm{C}$ for 10 min followed by amplification for 40 cycles $\left(95^{\circ} \mathrm{C}\right.$ for $15 \mathrm{sec}$ and $60^{\circ} \mathrm{C}$ for $60 \mathrm{sec}$ ). The solubility curve was 75 to $95^{\circ} \mathrm{C}$, warming $1^{\circ} \mathrm{C}$ per $20 \mathrm{sec}$. All of the real-time PCR reactions were performed in triplicate, glyceraldehyde-3-phosphate dehydrogenase (GAPDH)/beta-actin ( $\beta$-actin) was used as an internal control to normalize the data to determine the relative expression of the target genes. The relative change in gene expression was analyzed by the $2^{-\Delta \Delta C T}$ method. The PCR primers used in this study are described in Table I.

Western blotting analysis. To study the protein expression in the femur tissues, the femurs were dissected from the animals and immediately stored in liquid nitrogen. Protein concentrations were determined and equal amounts of the sample were loaded on SDS-polyacrylamide gel electrophoresis (PAGE). Samples were transferred onto nitrocellulose membranes after electrophoresis and separation. Membranes were blocked for $1 \mathrm{~h}$ in Tween 20 Tris-base sodium (TBST) containing 5\% milk followed by incubation with the appropriate primary antibody overnight at $4^{\circ} \mathrm{C}$. After washing 3 times in TBST, the membranes were incubated with goat anti-rabbit horse radish peroxidase- conjugated secondary antibodies (1:3,000; Wuhan Servicebio Technology. Co., Ltd. Wuhan, China) for $30 \mathrm{~min}$ at room temperature. Then, the membranes were washed 3 times in TBST at room temperature. All of the protein expression data were normalized by $\beta$-actin or GAPDH. The blots were visualized with ECL-plus reagent and the results were quantified by Lab Image v.2.7.1. The primary antibodies were used as follows: MSTN (EPR4567(2), ab124721), ActRIIB (EPR10739, ab180185) and Wnt (ab85060) were purchased from Abcam company. Smad2/3 (5678S), $\beta$-catenin (8480S), phospho-Smad2 (3108L), phospho-Smad3 (9520S), GSK-3 $\beta$ (27C10, 93158), and phospho-GSK-3 $\beta$ (D2Y9Y, 14630S) were purchased from Cell Signaling Technology, Inc., (Danvers, MA, USA). Dilution ratio of all the primary antibodies were $1: 1,000$.

Statistical analysis. Data are expressed as mean \pm SD. Statistical analyses were performed using SPSS v20.0 (SPSS, Inc., Chicago, IL, USA). The levels of statistical significance between the two groups were calculated using an unpaired Student's t test. $\mathrm{P}<0.05$ was considered to indicate a statistically significant difference. 
Table I. Nucleotide sequences of rat primers used for reverse transcription-quantitative polymerase chain reaction.

\begin{tabular}{|c|c|c|c|}
\hline Gene & Primer sequences $\left(5^{\prime}-3^{\prime}\right)$ & Product size (bp) & Annealing temperature $\left({ }^{\circ} \mathrm{C}\right)$ \\
\hline \multicolumn{4}{|c|}{ MSTN } \\
\hline $\mathrm{F}$ & TCTCAGACCCGTCAAGACTCCT & 260 & 60 \\
\hline $\mathrm{R}$ & CTCCTGGTCCTGGGAAGGTTAC & & \\
\hline \multicolumn{4}{|c|}{ ActRIIB } \\
\hline $\mathrm{F}$ & GCAGTCGTGGCAGAGTGAGCG & 127 & 60 \\
\hline $\mathrm{R}$ & CTTGAGGTAATCCGTGAGGGAGC & & \\
\hline \multicolumn{4}{|c|}{ Smad3 } \\
\hline $\mathrm{F}$ & CTGGCTACCTGAGTGAAGATGG- & 212 & 60 \\
\hline $\mathrm{R}$ & CTGTGAGGCGTGGAATGTCT & & \\
\hline \multicolumn{4}{|l|}{ Wnt } \\
\hline $\mathrm{F}$ & GCGTTCATCTTCGCAATCAC & 282 & 60 \\
\hline $\mathrm{R}$ & GCACTCTTGGCGCATCTCAG & & \\
\hline \multicolumn{4}{|c|}{$\beta$-catenin } \\
\hline $\mathrm{F}$ & GGACCCCAAGCCTTAGTAAACA & 286 & 60 \\
\hline $\mathrm{R}$ & TTATATCATCGGAACCCAGAAGC & & \\
\hline \multicolumn{4}{|c|}{ GSK-3 $\beta$} \\
\hline $\mathrm{F}$ & GCGTGAGGAGGGATAAGG- & 322 & 59 \\
\hline $\mathrm{R}$ & CACCAACAAGGGAGCAAAT & & \\
\hline \multicolumn{4}{|c|}{ GAPDH } \\
\hline $\mathrm{F}$ & AGGAGCGAGACCCCACTAACA & 247 & 60 \\
\hline $\mathrm{R}$ & AGGGGGGCTAAGCAGTTGGTC & & \\
\hline \multicolumn{4}{|c|}{ (1) } \\
\hline $\mathrm{F}$ & GTGACGTTGACATCCGTAAAGA & 287 & 60 \\
\hline $\mathrm{R}$ & GTAACAGTCCGCCTAGAAGCAC & & \\
\hline
\end{tabular}

F, forward; R, reverse; MSTN, myostatin; ActRIIB, Activin A Receptor Type 2B; Smad 3, mothers against decapentaplegic homolog 3; GSK-3 $\beta$, glycogen synthase kinase-3.
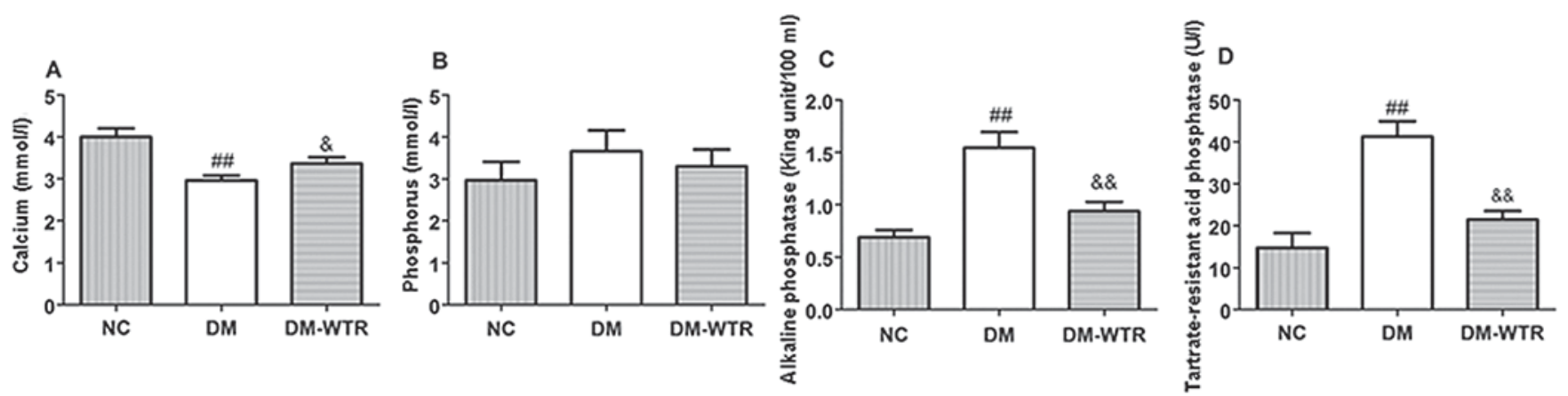

Figure 1. Effects of weight-bearing running on serum (A) $\mathrm{Ca}^{2+}$, (B) P, (C) ALP and (D) TRAP. Data are expressed as mean $\pm \mathrm{SD}$ ( $\mathrm{n}=8$ per group). ${ }^{\# \#} \mathrm{P}<0.01$ vs. NC; ${ }^{\circledR} \mathrm{P}<0.05,{ }^{\& \&} \mathrm{P}<0.01$ vs. DM.

\section{Results}

Weight-bearing running increases the body weight, muscle mass, bone mass, and grip strength of diabetic rats. The effects of weight-bearing running on body weight, muscle mass, bone mass, and grip strength in diabetic rats are depicted in Table II. Compared with the NC group, the body weight, muscle mass, bone mass, and grip strength of the DM group all decreased significantly $(\mathrm{P}<0.01)$. After six weeks of weight-bearing running, the body mass and bone mass were increased significantly compared with the DM group $(\mathrm{P}<0.05)$. Furthermore, weight-bearing running increased the muscle mass and grip strength significantly compared with the DM group of rats $(\mathrm{P}<0.01)$.

Weight-bearing running regulates the blood glucose and serum insulin of diabetic rats. The DM group had higher blood glucose compared with the NC group, and 
Table II. Effects of weight-bearing running on blood glucose, serum insulin, body weight, muscle mass, bone mass and grip strength

\begin{tabular}{lcrr}
\hline Group & \multicolumn{1}{c}{ NC } & DM & DM-WTR \\
\hline Blood glucose (mmol/l) & $4.88 \pm 1.01$ & $17.37 \pm 3.68^{\mathrm{a}}$ & $8.72 \pm 3.42^{\mathrm{a}, \mathrm{b}}$ \\
Serum insulin (mlU/l) & $21.33 \pm 4.06$ & $7.25 \pm 2.42^{\mathrm{a}}$ & $12.08 \pm 2.18^{\mathrm{a}, \mathrm{b}}$ \\
Body weight (g) & $371.32 \pm 24.23$ & $229.77 \pm 27.22^{\mathrm{a}}$ & $282.55 \pm 49.9^{\mathrm{a}, \mathrm{b}}$ \\
Bone mass (g) & $1.29 \pm 0.07$ & $0.72 \pm 0.15^{\mathrm{a}}$ & $0.90 \pm 0.12^{\mathrm{a}, \mathrm{b}}$ \\
Muscle mass (g) & $2.83 \pm 0.11$ & $1.44 \pm 0.14^{\mathrm{a}}$ & $2.18 \pm 0.63^{\mathrm{a}, \mathrm{c}}$ \\
Grip strength (N) & $1143.30 \pm 31.74$ & $800.79 \pm 141.29^{\mathrm{a}}$ & $1083.84 \pm 32.16^{\mathrm{c}}$ \\
\hline
\end{tabular}

Data are expressed as mean \pm standard deviation ( $\mathrm{n}=8$ per group). ${ }^{\mathrm{a}} \mathrm{P}<0.01 \mathrm{vs} . \mathrm{NC}$; ${ }^{\mathrm{b}} \mathrm{P}<0.05,{ }^{\mathrm{c}} \mathrm{P}<0.01 \mathrm{vs}$. DM, diabetic mellitus group; DM-WTR, diabetic exercise training group; $\mathrm{NC}$, negative control.
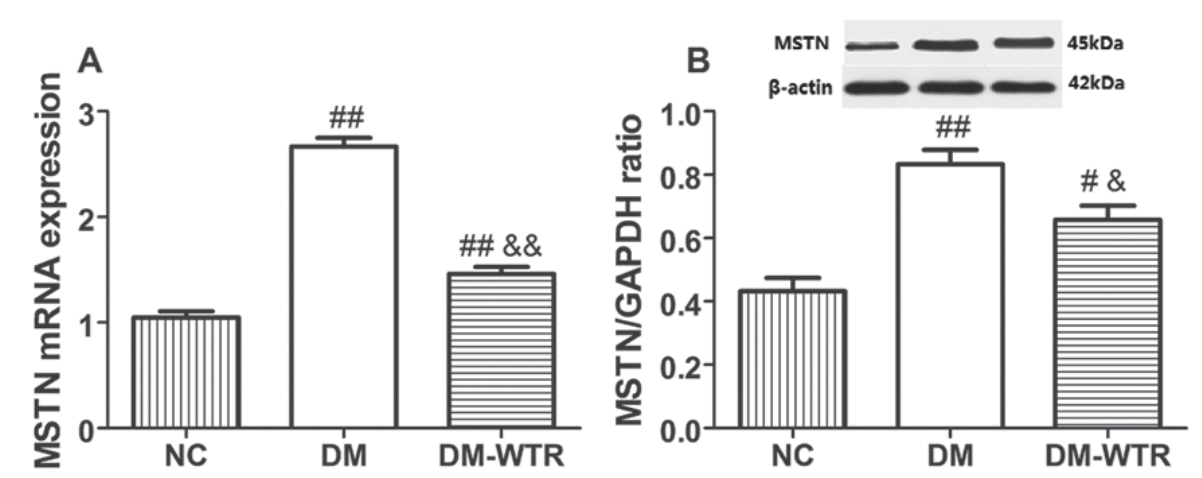

Figure 2. Effects of weight-bearing running on (A) STZ-induced mRNA and (B) protein expressions of MSTN in quadriceps femoris. Data are expressed as mean $\mathrm{SD}$ ( $\mathrm{n}=8$ per group) ${ }^{\prime \prime} \mathrm{P}<0.05,{ }^{\# \#} \mathrm{P}<0.01$ vs. $\mathrm{NC}$; ${ }^{\text {\& }} \mathrm{P}<0.05$, \&\& $\mathrm{P}<0.01$ vs. DM.

weight-bearing running showed significant improvements in this outcome $(\mathrm{P}<0.05)$. With respect to serum insulin levels, the DM group presented impaired serum insulin compared with nondiabetic rats $(\mathrm{P}<0.01)$. Weight-bearing running improved the insulin levels $(\mathrm{P}<0.05)$. These data are shown in Table II.

Weight-bearing running increases level of serum $\mathrm{Ca}^{2+}$ and reduces levels of serum ALP and TRAP of diabetic rats. As shown in Fig. 1, diabetes resulted in a significant decrease in serum $\mathrm{Ca}^{2+}(\mathrm{P}<0.01)$. In comparison with the DM group, 6 weeks of weight-bearing running significantly increased the secretions of serum $\mathrm{Ca}^{2+}(\mathrm{P}<0.05)$. There was no significant difference in serum $\mathrm{P}$ level between the rats in the $\mathrm{NC}$ group, the DM group, and the DM-WTR group. Serum ALP levels were significantly increased in diabetic non-treated animals $(\mathrm{P}<0.01)$ as compared to the NC group. Increased ALP levels confirm that diabetes induces bone damage. Serum ALP levels increased significantly in the DM-WTR groups $(\mathrm{P}<0.05)$ as compared to the DM group. This result shows that weight-bearing running treatment enhanced the bone formation and mineralization process in hyperglycemic conditions. When compared with the NC group, the serum levels of TRAP were significantly increased in the diabetic rats $(\mathrm{P}<0.01)$. The weight-bearing running treatment significantly decreased the serum levels of TRAP compared to the DM group $(\mathrm{P}<0.01)$.
Weight-bearing running inhibits MSTN expression in diabetic rats. We detected the MSTN expression in the quadriceps. The mRNA expression (Fig. 2A) and protein expression (Fig. 2B) of MSTN $(\mathrm{P}<0.01)$ in the DM group was significantly higher than that in the NC group. However, 6 weeks of weight-bearing running significantly reduced the mRNA and protein expressions of MSTN as compared to the DM rats $(\mathrm{P}<0.05$ and $\mathrm{P}<0.01$, respectively).

Weight-bearing running regulates the ActRIIB/Smad2/3 pathway in diabetic rats. The expression of ActRIIB and Smad2/3 and its phosphorylation were measured in the femurs. As shown in Fig. 3, the mRNA and protein expressions of ActRIIB $(\mathrm{P}<0.01$ and $\mathrm{P}<0.01$, respectively) in the $\mathrm{DM}$ group were all significantly higher than that in the NC group. After 6 weeks of weight-bearing running treatment, the mRNA and protein expressions of ActRIIB $(\mathrm{P}<0.05$ and $\mathrm{P}<0.05$, respectively) in the DM-WTR group were all significantly downregulated compared with that in the DM group (Fig. 3A and C). Similar to the above-mentioned results, the mRNA and protein expressions of $\operatorname{Smad} 2 / 3(\mathrm{P}<0.01$ and $\mathrm{P}<0.01$, respectively) in the DM group were all significantly higher than that in the NC group. After 6 weeks of weight-bearing running treatment, the mRNA and protein expressions of Smad2/3 $(\mathrm{P}<0.01$ and $\mathrm{P}<0.01$, respectively) in the DM-WTR group were all significantly downregulated compared with that in the DM group (Fig. 3B and D). Additionally, weight-bearing running 

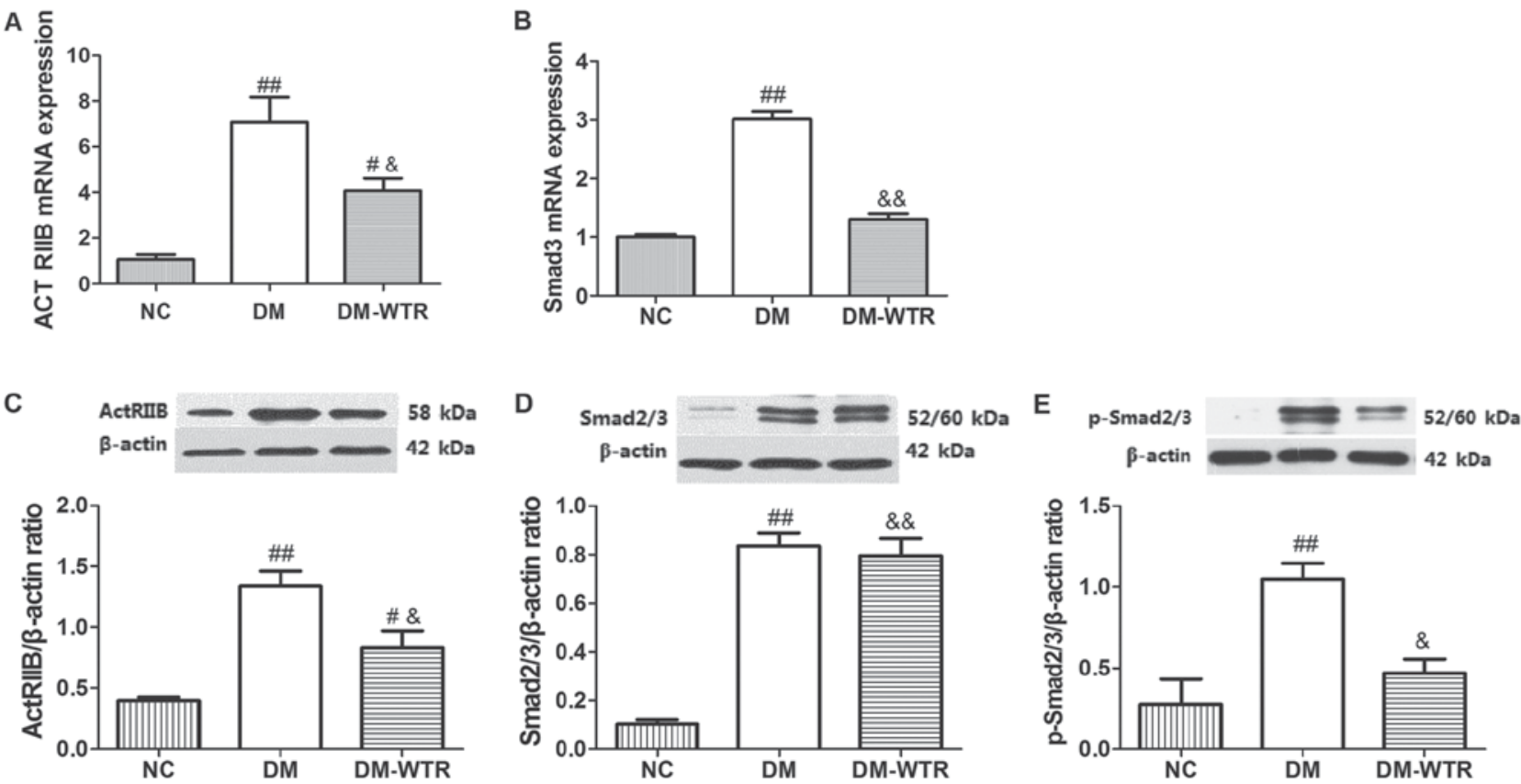

Figure 3. Effects of weight-bearing running on STZ-induced expression of ActRIIB, Smad2/3 and its phosphorylation in femora (A) ActRIIB mRNA expression, (B) Smad3 mRNA expression, (C) ActRIIB protein expression, (D) Smad2/3 protein expression and (E) Smad2/3 phosphorylation protein expression. Data are expressed as mean $\mathrm{SD}\left(\mathrm{n}=8\right.$ per group) ${ }^{\#} \mathrm{P}<0.05,{ }^{\#} \mathrm{P}<0.01$ vs. NC; ${ }^{\&} \mathrm{P}<0.05$, \&\& $\mathrm{P}<0.01$ vs. DM.

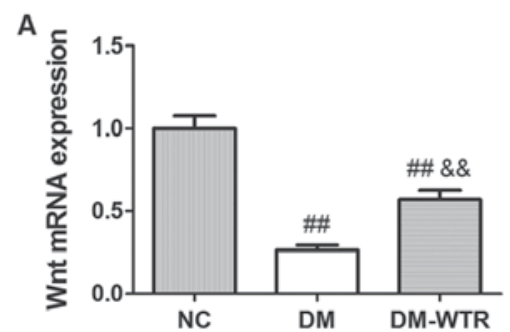

D
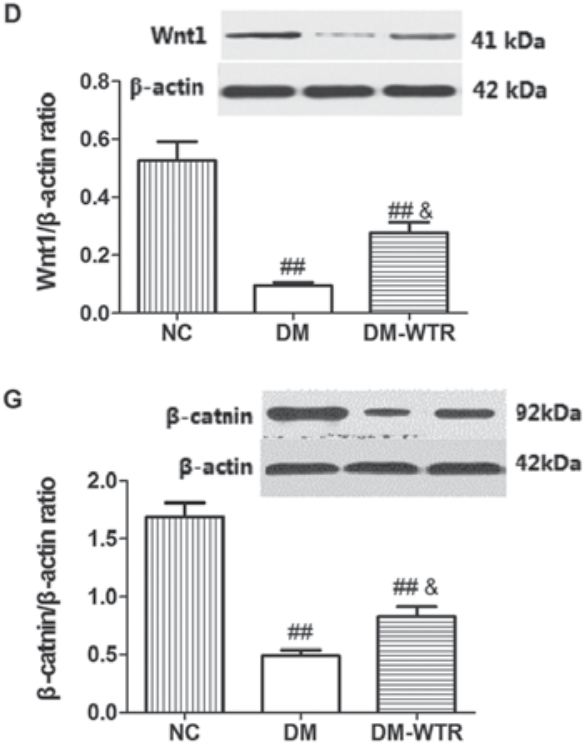

$B$

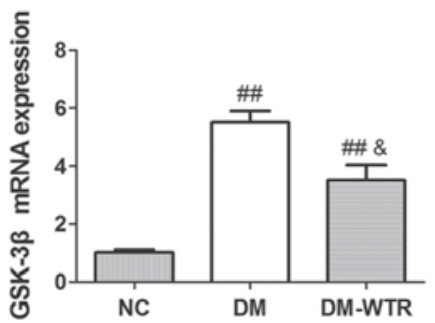

E

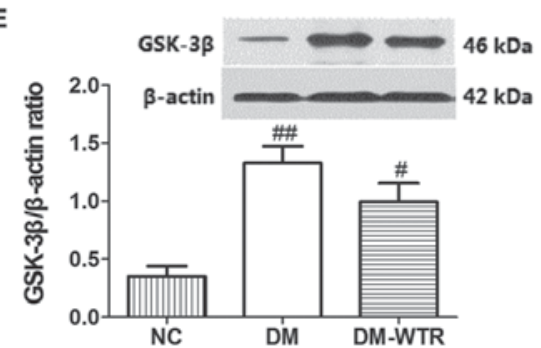

$c$
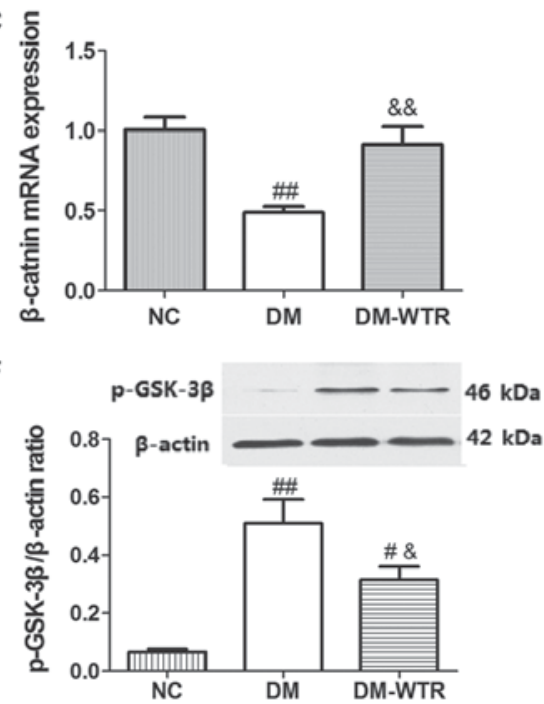

Figure 4. Effects of weight-bearing running on expressions of Wnt, GSK-3 $\beta$, p-GSK-3 $\beta$ and $\beta$-catnin in femora (A) Wnt mRNA expression, (B) GSK-3 $\beta$ mRNA expression, (C) $\beta$-catnin mRNA expression, (D) Wnt1 protein expression, (E) GSK-3 $\beta$ protein expression, (F) GSK-3 $\beta$ phosphorylation protein expression, (G) $\beta$-catnin protein expression. Data are expressed as mean $\mathrm{SD}\left(\mathrm{n}=8\right.$ per group) ${ }^{\#} \mathrm{P}<0.05,{ }^{\# \#} \mathrm{P}<0.01$ vs. NC; ${ }^{\&} \mathrm{P}<0.05$, \&\& $\mathrm{P}<0.01 \mathrm{vs}$. DM.

significant inhibited $(\mathrm{P}<0.05)$ the STZ-induced increase of expression of Smad2/3 phosphorylation (Fig. 3E). These results indicated that weight-bearing running maybe downregulated in the ActRIIB/Smad2/3 pathway. 


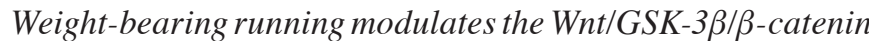
pathway in diabetic rats. The expression of Wnt, GSK-3 $\beta$ and its phosphorylation, and $\beta$-catenin and its phosphorylation were measured in the femurs. The mRNA and protein expressions of Wnt $(\mathrm{P}<0.01$ and $\mathrm{P}<0.01$, respectively) in the DM group were all significantly lower than that in the NC group. After 6 weeks of weight-bearing running treatment, the mRNA and protein expressions of $\mathrm{Wnt}(\mathrm{P}<0.01$ and $\mathrm{P}<0.05$, respectively) were significantly increased compared with the DM group (Fig. 4). The mRNA and protein expressions of GSK-3 $\beta$ ( $\mathrm{P}<0.01$ and $\mathrm{P}<0.01$, respectively) in the $\mathrm{DM}$ group were all significantly higher than that in the NC group. After 6 weeks of weight-bearing running treatment, the mRNA expression of GSK-3 $\beta(\mathrm{P}<0.05)$ was significantly inhibited compared with the DM group, and there was no significant difference between that in the DM group and the DM-WTR group (Fig. 4B and E). Additionally, weight-bearing running significant downregulated the STZ-induced increase of GSK-3 $\beta$ phosphorylation expression $(\mathrm{P}<0.05$; Fig. $4 \mathrm{~F})$. The mRNA and protein expressions of $\beta$-catenin $(\mathrm{P}<0.01$ and $\mathrm{P}<0.01$, respectively) in the DM group were all significantly lower than that in the NC group. After 6 weeks of weight-bearing running treatment, the mRNA and protein expressions of $\beta$-catenin $(\mathrm{P}<0.01$ and $\mathrm{P}<0.05$, respectively) were significantly increased compared with the DM group (Fig. 4C and G). These results indicated that weight-bearing running may be upregulated in the Wnt/GSK-3 $\beta / \beta$-catenin pathway.

\section{Discussion}

T1DM, also called insulin-dependent diabetes mellitus, is an autoimmune disease. It is associated with irreversible autoimmune destruction of pancreatic islet $\beta$-cells (13). T1DM is characterized by insulin deficiency and hyperglycemia, and it is one of the most common metabolic disorders in children and adolescents. Patients depend entirely on daily insulin injection replacement therapy to regulate their blood glucose levels (20). The etiology of T1DM is not completely understood, but genetic and environmental factors have been recognized as contributors to the development and progression of the disease (21).

Individuals with insufficient insulin therapy could influence the development of muscle function in T1DM patients. Furthermore, glycemic control is directly related to muscle metabolism and it could be an important determinant of muscle force and power in T1DM $(22,23)$. Skeletal disorders are common in diabetic patients, and many researchers have found that the patients had reduced bone mineral content $(24,25)$, deranged calcium and phosphate levels, and altered bone metabolism $(26,27)$. While it has been proven that aerobic and resistance training improves bone health $(28,29)$, there are only a few studies that have reported the effects of weight-bearing treadmill running on diabetes-induced bone loss. In accordance with the previous studies (30-32), we found that weight-bearing treadmill treatment reduced STZ-induced blood glucose, and increased STZ-induced blood insulin, weight mass, muscle mass, bone mass, and grip strength. Our results indicated that weight-bearing treadmill running treatment showed protective effects on rats with diabetic disease.
It has been reported that calcium concentration has been associated with diabetes (33). Calcium influx to $\beta$ cells can regulate the insulin secretion process, which is a calcium-dependent process $(34,35)$. It is possible that persistent alterations of calcium concentration could affect the insulin secretory response. In our study, weight-bearing treadmill running increased STZ-induced calcium excretion in serum, which is consistent with other findings in diabetic patients (36). Reports are variable about the high phosphorus level in T1DM (37). Diabetes may lead to kidney damage and the reduction of the renal excretion of phosphorus, which then causes a high phosphorus level. Our findings confirm earlier studies, but they did not show a statistically significant difference between the three groups; this might be because of the differences of the model animal. TRAP is a lysosomal hydrolyser, and it has been shown to be released from osteoclasts during bone resorption (38); this increase indicated excessive bone resorption in diabetic rats. In our study, weight-bearing treadmill running reduced STZ-induced TRAP levels in serum; these results were consistent with previous findings $(39,40)$. However, normal TRAP activity was also observed in the experimental diabetic animals (41). Even in another study, TRAP activity was found to be low in patients with T1DM (2). The reason lies in the differences of the study object and dosages of STZ.

Muscle and bone have a close relationship in not only anatomy but also in function. However, the mechanisms of their synergistic action are not completely known. The role of MSTN in muscle growth regulation and the disruption of its gene have been demonstrated to cause muscle hypertrophy and increase bone mass. Our previous work showed that blocking MSTN with a polyclonal anti-MSTN antibody preparation improves the trabecular bone microstructure (42), suggesting that therapeutic modulation of MSTN in vivo may be an effective strategy for preserving muscle mass and bone metabolism with diabetes. In the present study, weight-bearing running significantly inhibited STZ-induced MSTN expression, indicating that the inhibition of MSTN may alleviate STZ-induced diabetic muscle atrophy. However, the mechanism remains to be fully elucidated.

MSTN binds ActRIIB to activate signaling, ultimately resulting in Smad2/3 phosphorylation and translocation to the nucleus to modulate the transcription of numerous genes (43). ActRIIB and Smad 3 are the downstream signaling molecules of MSTN, and they have important roles in the regulation of bone metabolism $(44,45)$. Guo et al $(46)$, found that MSTN inhibited adipogenesis in human bone marrow-derived mesenchymal stem cells and mediated preadipocytes by activating $\mathrm{Smad} 3$, and cross-communication of the TGF $\beta / \mathrm{Smad}$ signaling to the $\mathrm{Wnt} / \beta$-catenin/TCF4 pathway partly, leading to the downregulation of PPAR $\gamma$. Our present study demonstrated that weight-bearing running reduced the STZ-induced expressions of ActRIIB and Smad2/3 in the femur. Moreover, weight-bearing running downregulated the expression of $\mathrm{p}-\mathrm{Smad} 2 / 3$, indicating that weight-bearing running inactivated Smad2/3 by possibly inhibiting ActRIIB expression, which was associated with MSTN downregulation.

The Wnt/GSK3 $\beta / \beta$-catenin signaling pathway controls a variety of life processes, including organism growth, development, diseases, aging, and death, as well as cell differentiation 
and the maintenance of form and function, immune, stress, cell carcinogenesis, and cell apoptosis (47). Study has shown that MSTN mediates cross-communication between Smad3 and $\mathrm{Wnt} / \beta$-catenin signaling pathways (46). Similar to our study, MSTN not only regulates Smad3 but also mediates Wnt/GSK3 $\beta / \beta$-catenin signaling pathway. However, the above-mentioned study also demonstrated that $\beta$-Catenin interacts with Smad3 and acts downstream of Smad3 to mediate the inhibitory effect of MSTN on adipogenesis (46). But, MSTN can inhibit directly expressions of Wnt and $\beta$-catenin to modulate femur atrophy under our control conditions. It is speculated that MSTN regulates $\operatorname{Smad} 3$ and $\mathrm{Wnt} / \beta$-catenin signaling pathway, which have organizational differences. Of course, the details also need further confirmation. MSTN may act upstream of the Wnt pathway and inhibit the expression of Wnt (48). The downstream signaling molecules of MSTN, such as ActRIIB and Smad3, are directly involved in the enhancement of $\beta$-catenin levels. Researchers have demonstrated that the Wnt/GSK3 $\beta / \beta$-catenin signaling pathway is involved in bone formation and contributes to osteoblastic differentiation (49). Our results demonstrated that weight-bearing running enhanced the STZ-induced Wnt and $\beta$-catenin expressions and reduced STZ-induced GSK-3 $\beta$ expression in diabetic rats' femora. Combined with the above-mentioned literature, we speculated that weight-bearing running may have activated the Wnt/GSK3 $\beta / \beta$-catenin signaling pathway possibly by the MSTN downregulation in the femur of diabetic rats.

Inconclusion, the presentstudy indicated that weight-bearing running could partially ameliorate STZ-induced femur atrophy by MSTN downregulation. and this may be associated with the inactivation of the ActRIIB/Smad2/3 signaling pathways and the activation of the Wnt/GSK3 $\beta / \beta$-catenin signaling pathway. Further studies are needed to confirm this.

\section{Acknowledgements}

The authors would like to thank the graduate students of the Institute of Sports Biology, Shaanxi Normal University (Shaanxi, China) for their cooperation, and College of Life Sciences, Shaanxi Normal University (Shaanxi, China), and Department of Physical Education, Xi'an University of Post and Telecommunications (Shaanxi, China).

\section{Funding}

The authors received no financial support for the research, authorship, and/or publication of the present study.

\section{Availability of data and materials}

The datasets used and/or analyzed during the present study are available from the corresponding author on reasonable request.

\section{Authors' contributions}

LT and SA conceived the present study. JY and LS performed the western blot analysis. BY and YK performed exercise training to all experimental animals, measured their body weight and grip strength, and collected blood and tissue samples. XF and LS performed the ELISA and RT-qPCR experiments, and collected and analyzed all data. JY prepared the manuscript, LS revised it critically for important intellectual content, and all authors were involved in the writing and editing of the manuscript.

\section{Ethics approval and consent to participate}

All of the experiments were conducted with the approval of the Ethics Committee of Shaanxi Normal University and in accordance with the Guide for the Care and Use of Laboratory Animals published by the US National Institutes of Health (NIH Publication no. 85-23, revised 1996).

\section{Patient consent for publication}

Not applicable.

\section{Competing interests}

The authors declare that they have no competing interests.

\section{References}

1. Kemink SA, Hermus AR, Swinkels LM, Lutterman JA and Smals AG: Osteopenia in insulin-dependent diabetes mellitus; prevalence and aspects of pathophysiology. J Endocrinol Invest 23: 295-303, 2000.

2. Campos Pastor MM, López-Ibarra PJ, Escobar-Jiménez F, Serrano Pardo MD and García-Cervigón AG: Intensive insulin therapy and bone mineral density in type 1 diabetes mellitus: A prospective study. Osteoporos Int 11: 455-459, 2000.

3. Erdal N, Gürgül S, Demirel C and Yildiz A: The effect of insulin therapy on biomechanical deterioration of bone in streptozotocin (STZ)-induced type 1 diabetes mellitus in rats. Diabetes Res Clin Pract 97: 461-467, 2012.

4. López-Ibarra PJ, Pastor MM, Escobar-Jiménez F, Pardo MD, González AG, Luna JD, Requena ME and Diosdado MA: Bone mineral density at time of clinical diagnosis of adult-onset type 1 diabetes mellitus. Endocr Pract 7: 346-351, 2001.

5. Roggen I, Gies I, Vanbesien J, Louis O and De Schepper J: Trabecular bone mineral density and bone geometry of the distal radius at completion of pubertal growth in childhood type 1 diabetes. Horm Res Paediatr 79: 68-74, 2013.

6. Saha MT, Sievänen H, Salo MK, Tulokas S and Saha HH: Bone mass and structure in adolescents with type 1 diabetes compared to healthy peers. Osteoporos Int 20: 1401-1406, 2009.

7. Albright F: Bone development in diabetic children: A roentgen study. Am J Med Sci 174: 313-319, 1948.

8. Diabetes Control and Complications Trial Research Group, Nathan DM, Genuth S, Lachin J, Cleary P, Crofford O, Davis M, Rand $\mathrm{L}$ and Siebert C: The effect of intensive treatment of diabetes on the development and progression of long-term complications in insulin-dependent diabetes mellitus. N Engl J Med 329: 977-986, 1993.

9. Moy CS, Songer TJ,LaPorte RE,Dorman JS, Kriska AM, Orchard TJ, Becker DJ and Drash AL: Insulin-dependent diabetes mellitus, physical activity, and death. Am J Epidemiol 137: 74-81, 1993.

10. Kriska AM, LaPorte RE, Patrick SL, Kuller LH and Orchard TJ: The association of physical activity and diabetic complications in individuals with insulin-dependent diabetes mellitus: The Epidemiology of Diabetes Complications Study-VII. J Clin Epidemiol 44: 1207-1214, 1991.

11. Yee CS, Xie L, Hatsell S, Hum N, Murugesh D, Economides AN, Loots GG and Collette NM: Sclerostin antibody treatment improves fracture outcomes in a Type I diabetic mouse model. Bone 82: 122-134, 2016.

12. Rodda SJ and McMahon AP: Distinct roles for Hedgehog and canonical Wnt signaling in specification, differentiation and maintenance of osteoblast progenitors. Development 133: 3231-3244, 2006. 
13. Espe K, Galler A, Raila J, Kiess W and Schweigert FJ: High-normal C-reactive protein levels do not affect the vitamin A transport complex in serum of children and adolescents with type 1 diabetes. Pediatr Res 62: 741-745, 2007.

14. Funaba M, Ogawa K and Abe M: Expression and localization of activin receptors during endochondral bone development. Eur J Endocrinol 144: 63-71, 2001.

15. Amthor H, Macharia R, Navarrete R, Schuelke M, Brown SC, Otto A, Voit T, Muntoni F, Vrbóva G, Partridge T, et al: Lack of myostatin results in excessive muscle growth but impaired force generation. Proc Natl Acad Sci USA 104: 1835-1840, 2007.

16. Bialek P, Parkington J, Li X, Gavin D, Wallace C, Zhang J, Root A, Yan G, Warner L, Seeherman HJ and Yaworsky PJ: A myostatin and activin decoy receptor enhances bone formation in mice. Bone 60: 162-171, 2014

17. Tang L, Gao X, Yang X, Liu C, Wang X, Han Y, Zhao X, Chi A and Sun L: Ladder-climbing training prevents bone loss and microarchitecture deterioration in diet-induced obese rats. Calcif Tissue Int 98: 85-93, 2016.

18. Tang L, Gao X, Yang X, Zhang D, Zhang X, Du H, Han Y and Sun L: Combination of weight-bearing training and anti-MSTN polyclonal antibody improve bone quality in rats. Int J Sport Nutr Exerc Metab 26: 516-524, 2016.

19. Wan CX, Xu M, Huang SH, Wu QQ, Yuan Y, Deng W and Tang QZ: Baicalein protects against endothelial cell injury by inhibiting the TLR4/NF- $\kappa$ B signaling pathway. Mol Med Rep 17 3085-3091, 2018.

20. Balamurugan AN, Bottino R, Giannoukakis N and Smetanka C: Prospective and challenges of islet transplantation for the therapy of autoimmune diabetes. Pancreas 32: 231-243, 2006

21. Hirschhorn JN: Genetic epidemiology of type 1 diabetes. Pediatr Diabetes 4: 87-100, 2003

22. Aftab Guy D, Sandoval D, Richardson MA, Tate D and Davis SN: Effects of glycemic control on target organ responses to epinephrine in type 1 diabetes. Am J Physiol Endocrinol Metab 289: E258-E265, 2005.

23. Corigliano G, Iazzetta N, Corigliano M and Strollo F: Blood glucose changes in diabetic children and adolescents engaged in most common sports activities. Acta Biomed 77 (Suppl 1): S26-S33, 2006.

24. Levin ME, Boisseau VC and Avioli LV: Effects of diabetes mellitus on bone mass in juvenile and adult-onset diabetes. $\mathrm{N}$ Engl J Med 294: 241-245, 1976.

25. Santiago JV, McAlister WH, Ratzan SK, Bussman Y, Haymond MW, Shackelford G and Weldon VV: Decreased cortical thickness \& osteopenia in children with diabetes mellitus. J Clin Endocrinol Metab 45: 845-848, 1977.

26. Heath H III, Lambert PW, Service FJ and Arnaud SB: Calcium homeostasis in diabetes mellitus. J Clin Endocrinol Metab 49: 462-466, 1979.

27. McNair P, Madsbad S, Christiansen C, Faber OK, Transbøl I and Binder C: Osteopenia in insulin treated diabetes mellitus. Its relation to age at onset, sex and duration of disease. Diabetologia 15: 87-90, 1978.

28. Almstedt HC, Grote S, Korte JR, Perez Beaudion S, Shoepe TC, Strand S and Tarleton HP: Combined aerobic and resistance training improves bone health of female cancer survivors. Bone Rep 5: 274-279, 2016.

29. Gomes TS, Aoike DT, Baria F, Graciolli FG, Moyses RMA and Cuppari L: Effect of aerobic exercise on markers of bone metabolism of overweight and obese patients with chronic kidney disease. J Ren Nutr 27: 364-371, 2017.

30. Junod A, Lambert AE, Stauffacher W and Renold AE: Diabetogenic action of streptozotocin: Relationship of dose to metabolic response. J Clin Invest 48: 2129-2139, 1969.

31. Li RJ, Qiu SD, Tian H and Zhou SW: Diabetes induced by multiple low doses of STZ can be spontaneously recovered in adult mice. Dongwuxue Yanjiu 34: 238-243, 2013 (In Chinese).

32. Tsai CC, Chan P, Chen LJ, Chang CK, Liu Z and Lin JW: Merit of ginseng in the treatment of heart failure in type 1-like diabetic rats. Biomed Res Int 2014: 484161, 2014.
33. Jorde R, Schirmer H, Njolstad I, Løchen ML, Bøgeberg Mathiesen E, Kamycheva E, Figenschau Y and Grimnes G: Serum calcium and the calcium-sensing receptor polymorphism rs17251221 in relation to coronary heart disease, type 2 diabetes, cancer and mortality: The Troms $\varnothing$ Study. Eur J Epidemiol 28: 569-578, 2013.

34. Henquin JC: Triggering and amplifying pathways of regulation of insulin secretion by glucose. Diabetes 49: 1751-1760, 2000.

35. Pittas AG, Lau J, Hu FB and Dawson-Hughes B: The role of vitamin $\mathrm{D}$ and calcium in type 2 diabetes. A systematic review and meta-analysis. J Clin Endocrinol Metab 92: 2017-2029, 2007.

36. Mosso C, Hodgson MI, Ortiz T and Reyes ML: Bone mineral density in young Chilean patients with type 1 diabetes mellitus. J Pediatr Endocrinol Metab 29: 731-736, 2016.

37. Hamed EA, Faddan NH, Elhafeez HA and Sayed D: Parathormone-25(OH)-vitamin D axis and bone status in children and adolescents with type 1 diabetes mellitus. Pediatr Diabetes 12: 536-546, 2011.

38. Halleen JM, Tiitinen SL, Ylipahkala H, Fagerlund KM and Väänänen HK: Tartrate-resistant acid phosphatase $5 \mathrm{~b}$ (TRACP 5b) as a marker of bone resorption. Clin Lab 52: 499-509, 2006.

39. Rao Sirasanagandla S, Ranganath Pai Karkala S, Potu BK and Bhat KM: Beneficial effect of cissus quadrangularis Linn. on osteopenia associated with streptozotocin-induced type 1 diabetes mellitus in male wistar rats. Adv Pharmacol Sci 2014: $483051,2014$.

40. Gopalakrishnan V, Arunakaran J, Aruldhas MM and Srinivasan N: Effects of streptozotocin-induced diabetes mellitus on some bone turnover markers in the vertebrae of ovary-intact and ovariectomized adult rats. Biochem Cell Biol 84: 728-736, 2006

41. Waud CE, Marks SC Jr, Lew R and Baran DT: Bone mineral density in the femur and lumbar vertebrae decreases after twelve weeks of diabetes in spontaneously diabetic-prone BB/worcester rats. Calcif Tissue Int 54: 237-240, 1994.

42. Tang L, Yang X, Gao X, Du H, Han Y, Zhang D, Wang Z and Sun L: Inhibiting myostatin signaling prevents femoral trabecular bone loss and microarchitecture deterioration in diet-induced obese rats. Exp Biol Med (Maywood) 241: 308-316, 2016

43. Arounleut P, Bialek P, Liang LF, Upadhyay S, Fulzele S, Johnson M, Elsalanty M, Isales CM and Hamrick MW: A myostatin inhibitor (propeptide-Fc) increases muscle mass and muscle fiber size in aged mice but does not increase bone density or bone strength. Exp Gerontol 48: 898-904, 2013.

44. Inoue Y, Canaff L, Hendy GN, Hisa I, Sugimoto T, Chihara K and Kaji H: Role of Smad3, acting independently of transforming growth factor-beta, in the early induction of Wnt-beta-catenin signaling by parathyroid hormone in mouse osteoblastic cells. J Cell Biochem 108: 285-294, 2009.

45. Lerner UH and Ohlsson C: The WNT system: Background and its role in bone. J Intern Med 277: 630-649, 2015.

46. Guo W, Flanagan J, Jasuja R, Kirkland J, Jiang L and Bhasin S: The effects of myostatin on adipogenic differentiation of human bone marrow-derived mesenchymal stem cells are mediated through cross-communication between Smad3 and Wnt/beta-catenin signaling pathways. J Biol Chem 283: 9136-9145, 2008.

47. Liu JD, Deng Q, Tian HH, Pang YT and Deng GL: Wnt/glycogen synthase kinase $3 \beta / \beta$-catenin signaling activation mediated sevoflurane preconditioning-induced cardioprotection. Chin Med J (Engl) 128: 2346-2353, 2015.

48. Steelman CA, Recknor JC, Nettleton D and Reecy JM: Transcriptional profiling of myostatin-knockout mice implicates Wnt signaling in postnatal skeletal muscle growth and hypertrophy. FASEB J 20: 580-582, 2006.

49. Day TF, Guo X, Garrett-Beal L and Yang Y: Wnt/beta-catenin signaling in mesenchymal progenitors controls osteoblast and chondrocyte differentiation during vertebrate skeletogenesis. Dev Cell 8: 739-750, 2005. 